\title{
Extra nodal Lymphoma(Thyroid Lymphoma)- FNAC Diagnosis
}

\author{
M MOMIN
}

(J Bangladesh Coll Phys Surg 2018; 36: 82)

DOI: http://dx.doi.org/10.3329/jbcps.v36i2.36072

A 62 year old male pateient presented with abdominal mass, jaundice and swelling in front of neck and right axilla.ON FNAC from thyroid and axilla show monotonous population of cells suggestive of lymphoma. Further histological examination of excise axillary lymph nodeconfirmed Non-Hodgkins lymphoma Bcell type. Patient treated with chemotherpy and after cycle three all lymph node with throid swelling subsides.

Figure: A; Thyroid swelling(red arrow) \& Right axillary swelling (grey arrow) B; FNAC Thyroid show monotonous round cells $\mathrm{C}$; FNAC Axillary node show nmonotonous round cells.

A 62 -year old male came to surgery outpatient department of Yashoda hospital, Hyderabad, India, in May 2015 with history of yellowish discoloration for 15 days,swelling in front neck,loss of apetite and loss of weight. Out side investigations show jaundice and ultrasound abdomen suggestive of pancreatic mass with significant IHBR dilation. At presentation, Clinically he had fever, icterus and swelling in front of neck,moves with deglutition \& right axillary lymph node noted (Fig
1 A).CT scan of chest and abdomen showed Thyromegaly with Retrosternal extension, right Axillary lymphadenopathy, pancreatic mass lesion with dilated IHBR and prominent main pancreatic duct. Para-aortic, Retroperitoneal, mesenteric lymphnodes .

Fine needle aspiration cytology (FNAC) from thyroid and right axillary lymph node done which showed monotonous population of lymphocytes with two to three times larger than mature lymphocytes and fine chromatin (Fig 1B \& C) favour lymphoproliferative disorder lymphoma.

Right axillary lymph node biopsy with IHC study showed High grade non-hodgkin lymphoma B cell type. Chemotherapy (CHOP) \&Radiation Oncologist was consulted and patient was started on Palliative RT to neck in view of critical compression of trachea. Patient tolerated chemotherapy \& radiotherapy well and after third cycle patient thyroid swelling completely subsided. His LFT come down to with in normal range. Presently patient in follow up with no recurrence of thyroid and axillary lymph node.
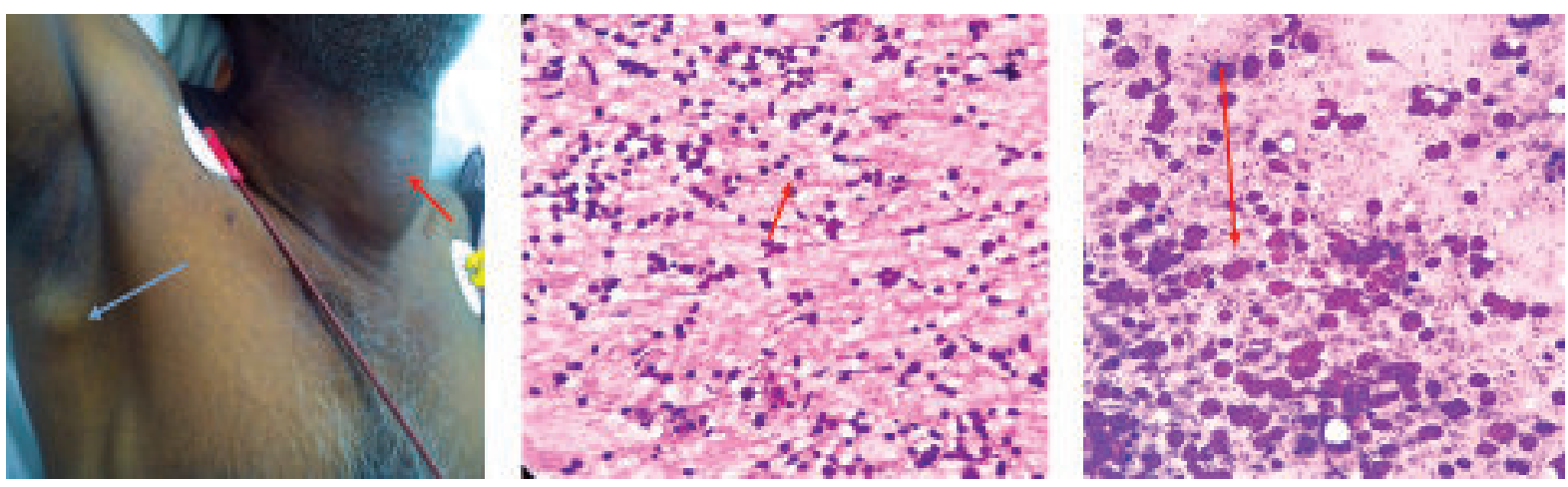

Fig.: A. Thyroid swelling(red arrow) \& Right axillary swelling (grey arrow); B. FNAC Thyroid show monotonous round cells; C. FNAC Axillary node show nmonotonous round cells.

Dr. Majed Momin, Consultant Pathologist, Dept. of Laboratory Medicine, Yashoda Hospitals, Malakpet, Nalgonda Cross road, Hyderabad500036, email:majedmomin9@gmail.com 